\title{
Development and Application of a Distributed Leadership Framework to the Curriculum Mapping of Quantitative Skills in First-Year Undergraduate Agriculture Degrees
}

\author{
Janelle Wilkes $^{\mathrm{a}}$ and Jackie Reid ${ }^{\mathrm{b}}$ \\ Corresponding author: Janelle Wilkes (jwilkes@une.edu.au)

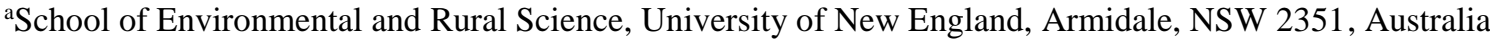 \\ ${ }^{\mathrm{b} S} \mathrm{School}$ of Science and Technology, University of New England, Armidale, NSW 2351, Australia
}

Keywords: agriculture, mathematics, course mapping, shared leadership, collaborative leadership, first year experience

International Journal of Innovation in Science and Mathematics Education, 27(4), 14-26, 2019

Special Issue: Agricultural Education

\begin{abstract}
Quantitative skills (QS), the ability to use mathematical and statistical reasoning in context, are considered essential threshold learning outcomes in Australian university agricultural courses (degrees). Curriculum mapping can be used to determine how the existing curriculum fosters the development of QS, and identify where opportunities for skills development are missing in the curriculum. To address the challenges of curriculum mapping this paper describes the development and application of a modified distributed leadership model based on the merging of Kotter's eight steps for structural change (2014) and Jones, Hadgraft, Harvey, Lefoe and Ryland's framework for distributed leadership (2014). Distributed leadership is built on the foundations of change theory, moving beyond the traditional leadership boundaries and has been increasingly used in higher education. This case study demonstrates how distributed leadership has been used successfully in determining the graduate level QS and driving the mapping process for the first-year curriculum. Curriculum maps showed when the QS were taught, practiced and assessed across 10 science degrees, including three agriculture degrees, at a regional Australian university. As a result, holistic curriculum changes were flagged with the aim of enhancing QS development for both on campus and distance learning students.
\end{abstract}

\section{Introduction}

Agriculture and related disciplines are taught in 14 Australian Universities as three and fouryear specialist courses (degrees). Agricultural courses include a wide range of degrees and subdisciplines including agricultural science, animal science, horticulture, viticulture and oenology, agribusiness and agricultural economics (Botwright Acuña, Able, Kelder, Bobbi, Guisard, Bellotti, McDonald, Doyle, Wormell, \& Meinke, 2014).

The need for the development of Quantitative Skills (QS) in agriculture is clearly articulated in the Threshold Learning Outcomes (TLOs) by Botwright Acuña et al. (2014): 'Demonstrating knowledge of the core sciences [including mathematics and statistics] in the context of agriculture' (p. 7), and 'Collecting, accurately recording, analysing, interpreting and reporting data' (p. 7) including applying 'mathematics and statistical approaches to refine and interpret 
data' (p. 11). 'Fundamental mathematical and quantitative skills are critical for agriculture students to succeed in their studies and careers' (Gupta \& Adams, 2016; p.5).

Universities need to determine the mathematical background of their students to provide the appropriate level of support to help them develop the relevant QS. In addition, universities need to have a clear understanding of the QS required of their graduates and thus be able to scaffold these skills. Curriculum maps are useful in showing the development of QS across degrees. Quantitative Skills are mentioned in the TLOs for agriculture, which have been mapped for two agriculture degrees at two Australian universities (Botwright Acuña et al., 2016). Reid and Wilkes (2016) defined 43 graduate QS and mapped the QS in first-year units across 10 science degrees, including three agriculture degrees. In this paper we describe a case study where we used a merged conceptual distributed leadership framework to successfully map the QS across the first-year curriculum. Both the merged conceptual distributed leadership framework and its application could be adapted for curriculum mapping projects at other institutions.

\section{Quantitative skills}

Quantitative Skills (QS) are defined as the ability to apply mathematical and statistical thinking and reasoning in context (Matthews, Belward, Coady, Rylands, \& Simbag, 2012). To meet future global food requirements agricultural graduates need to be flexible problem solvers, and utilise advanced technology based on a strong grounding in QS (Gupta \& Adams, 2016). The increased demand for graduates with QS has been accompanied by a decline in students' mathematical preparedness in Australia (Barrington 2013; King \& Cattlin, 2014) and internationally (e.g. Jaafar, Toce, \& Polnariev, 2016). This has resulted in a focus in the literature on the development of QS for science students (Matthews et al., 2012).

The number of students studying intermediate and advanced mathematics has declined since 1995 (Barrington, 2013; Brown, 2009). The reasons for this decline are complex but in part may be due to cultural attitudes, unavailability of subjects at school and the lack of prerequisites for entry into science-based degrees at many universities (Advocacy Australian Mathematical Sciences Institute, 2015). Consequently, many students are mathematically underprepared when enrolling in science-based degrees, including agriculture.

\section{Curriculum mapping}

A curriculum map is a strategic aid in the curriculum development process and has been described extensively (e.g. Nicholls \& Nicholls, 1981). It can be used to identify how the existing curriculum fosters the development of, in this case, QS, where opportunities for skills development are missing or where overlap exists in the curriculum (Fallows \& Steven, 2000). One of the major challenges when conducting a curriculum mapping exercise is gaining buyin from time-poor academics. Staff may not engage with the process if they view the curriculum mapping exercise as a possible course-cutting exercise, a criticism of their teaching, or as another addition to their already heavy workload (Lawson, Taylor, Fallshaw, French, Hall, Kinash, \& Summers, 2013). Successful mapping projects require management of 'change for effective staff buy-in and adoption' (Lawson et al., 2013; p.44).

\section{Change theory}

Kotter's work on organisational change is highly regarded for his use of real-world examples for management practitioners (Clay, 2017). To encourage wide spread change in an organisation there is a need to create urgency around the issue, where: staff see the need for change so they can visualise problems and solutions; feel the reality of their situation and need to act; and then, due to their emotional involvement, act to create change. Staff also need to build a guiding team, form a strategic vision and initiatives, enlist volunteers, enable actions 
by removing barriers, create momentum through short-term wins, sustain acceleration to ensure waves of change can occur and finally institute change (Kotter, 2014).

Change theory and leadership theory are closely intertwined (Knight \& Trowler, 2001). Change theory, of necessity, underpins theories of leadership (Yielder \& Codling, 2004). Within the context of higher education, leaders need to be inspirational and motivational to bring about change that is desirable, at least by some; or to challenge undesirable change (Knight \& Trowler, 2001). For most university Schools or Faculties, achieving consensus on important issues is impossible, and waiting for this to occur can grind change to a halt. However, imposing change during opposition leads to increased opposition, time delays, and noncompliances. Distributed leadership is a strategy that endeavours to engage with the divergent views, understandings and characteristics of those in the change project (Ramsden, 1988).

Lawson et al. (2013) implemented the seven strategies for cultural change by Kotter and Cohen (2002), in a national curriculum-mapping project. This research project evaluated and critically reviewed how graduate attributes were mapped in Australian universities. They found institutions that took a top down approach, focussing on accreditation, struggled to gain staff buy-in. In contrast, universities striving for continuous improvement, where mapping was part of their normal business, used a participative leadership style (Lawson et al., 2013), such as distributed leadership, resulting in higher staff engagement. Furthermore, collaborative workshops that encourage peer-to-peer interactions enable individual academics to gain a more holistic view of how the degree meets the TLOs (Botwright Acuña, McDonald, Kelder, \& Able, 2016).

\section{Distributed leadership}

The first explicit reference to distributed leadership was in 1954 (Gronn, 2002); but it was Gronn (2002) that provided a deep theoretical background to distributed leadership, with his article being cited over 1000 times. Four principles encapsulate Gronn's (2002) definition of distributed leadership, and these will be used in this paper. Distributed leadership: is an emergent property of a group or network of interacting individuals; moves beyond traditional leadership boundaries; includes ranges of expertise that are distributed across the many, not the few; and can arise from formal structures and/or emergent interpersonal interactions where the champions do not need to have positional leadership roles.

When using a distributed leadership approach there is a shift in focus away from the attributes and behaviours of the individual ('heroic') leaders. Distributed leaders have a more systematic perspective, as leadership is shown through the collective social process that emerges through the interactions of multiple actors (Bolden, 2011), and is not leaderless but rather 'leaderful' (Vanderslice, 1988 cited in Knight \& Trowler, 2001). What transpires in distributed leadership is that the leaders assist others to lead themselves (Knight \& Trowler, 2001).

Distributed leadership, first used in schools and increasing in popularity since the start of the millennium, has become more widely adopted in higher education (Bennett, Wise, Woods, \& Harvey, 2003; Bolden, 2011) in the contexts of research, and learning and teaching. 'Relationships are central to the effective use of distributed leadership as it is based upon the idea of influence rather than direction' (Boud, Brew, Dowling, Kiley, McKenzie, Malfroy, Ryland, \& Solomon, 2014, p.442). In the higher education research context a culture of 'autonomy and respect rather than control is one of the markers of where distributed leadership can be effective' (Boud et al., 2014, p.442). Gosling, Bolden and Petrov (2009) found distributed leadership in higher education does not replace individual leadership, but rather complements it. They expressed concern that with rising distributed leadership in higher education there has been a move from collegial to more managerial administration methods, 
leading to decrease in committee powers. However, the distributed leadership approach has highlighted organisation processes in leadership; with Jones et al. (2014) finding, in the context of leadership in learning and teaching, that a distributed leadership framework enables people to engage.

\section{Background}

\section{UNE context}

The University of New England (UNE) is a large regional university with a diverse range of students studying on-campus and at a distance. UNE has over $60 \%$ of science students studying at a distance, including international and overseas students. Agriculture has been taught at UNE since the 1950 s, and $70 \%$ of students study on-campus, with the remainder studying by distance but with the requirement to attend intensive (3-5 day) schools on-campus per unit. Many students come from lower socio-economic backgrounds, are mature age, and may enrol through special entry schemes. To improve the first-year student experience at UNE a whole-ofinstitution approach was adopted (Kift, Nelson, \& Clarke, 2010). As part of this approach, the authors became the First-Year Teaching and Learning Coordinators for the two science schools and collaborated on a number of projects, including the QS curriculum-mapping project discussed here.

\section{The QS Mapping Project (Project)}

The Project was designed to map QS across the first-year science units, while addressing issues that may affect students' development of QS for both on-campus and distance modes of study. Reid and Wilkes (2016) describe the mapping process in detail. In the following sections, the authors will describe how the QS Project aligns with the merged distributed leadership framework.

\section{Merged Conceptual Framework}

In the Project the authors merged the updated eight steps of change (Kotter, 2014) with the benchmarking framework for distributed leadership (Jones et al., 2014). Figure 1 shows the compatibility of many of the terms from Kotter (2014) with that of Jones et al. (2014). Kotter's Steps 4 to 8 align with the distributed leadership framework proposed by Jones et al. (2014). However, Kotter (2014) also includes three additional preliminary steps for change including creating a sense of urgency, building a guiding coalition and forming a strategic vision and initiatives. Outcomes 1,2 and 3 have been included in the resultant Merged Conceptual Framework to emphasise that to gain success distributed leadership projects need to build on the foundations of cultural change theory.

\section{Evidence collected to evaluate the Merged Conceptual Framework}

A wide range of evidence should be used to evaluate distributed leadership projects (Jones et al. 2014). In the Project both formal and informal evidence was collected and reflected upon. Evidence collected included:

1. Over 20 emails from University Senior Management stating the merits of the Project and requesting staff participation.

2. Participation rate and recordings from independent observers (conversations and interactions) of staff at including Initial Workshop; Call-to-action Seminar; Disciplinebased Workshops; Mapping Workshops; Course-based Workshops for the 10 science degrees mapped; and Interviews of science first-year unit coordinators regarding how QS could be better incorporated into the curriculum. 
3. Online final Formal Questionnaire, which included open-ended and Likert-scale questions, where the Project was evaluated by participants.

4. Publications and conference presentations from the Project.

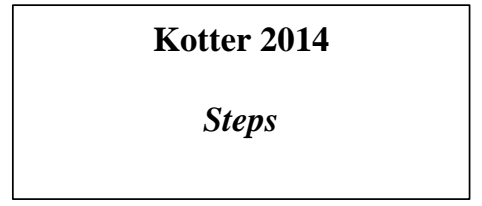

1. Create a sense of urgency

2. Build a guiding coalition

3. Form a strategic vision and initiatives

4. Enlist a volunteer army

5. Enable action by removing barriers

\section{Generate short-term} wins

\section{Sustain acceleration}

8. Institute change

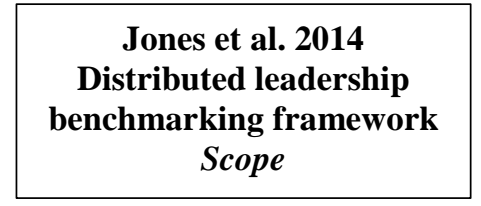

1. Engage a broad range of participants from formal leaders, informal leaders, and experts; discipline experts and functional experts.

2. Enable through a context of trust, a culture of respect, an acceptance of change, and building collaborative relationships.

3. Enact through the involvement of people, the design of processes, the provision of support and the implementation of systems.

4. Assess (evaluate) via various sources of evidence showing increased engagement, increased collaboration and growth in leadership capacity.

5. Emergent and sustained through reflective practice and cycles of action research.

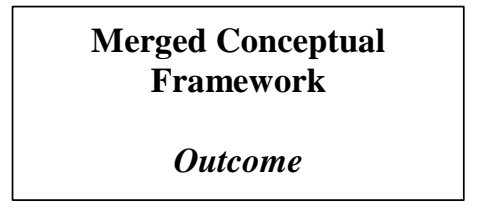

1. Intra- \& inter-

urgency, increase

2. Guiding team, build

3. Vision, form a strategic vision and initiatives

4. Engage a wide range of formal \& informal leaders/experts; discipline/ functional experts; gaining executive support.

5. Enable action by removing barriers, by creating a context of trust, a culture of respect, an acceptance of change, and building collaborative relationships.

6. Enact through involvement of people, design of processes, support (generate short term wins), and implementation of systems.

7. Assess (evaluate) via various sources of evidence showing increased engagement, increased collaboration and growth in leadership capacity.

8. Emergent and sustained change through reflective practice leading to institutional change.

Figure 1: Merged Conceptual Framework showing the integration of the eight steps of change (Kotter, 2014) and the Distributed Leadership Benchmarking Framework (Jones et al., 2014). 
In addition, the authors kept journals that informed reflection on, and refinement of the Project. This allowed us to reflect-on-action (Leitch \& Day, 2000). This included reflection on the emergence of our own leadership roles as a result of our First-Year Coordinator positions, and our leadership of the QS Project. As part of this reflection, the authors gave two conference presentations: one on our collaborative journey and another on leadership in the academy.

\section{Alignment of the Project with the Merged Conceptual Framework}

In the following, the authors define the outcomes from the Merged Conceptual Framework given in Figure 1, demonstrate how the Project aligns with the Framework (Table 1), and include detailed examples that relate to the mapping of QS in agriculture degrees.

\section{Outcome 1: Intra-urgency and inter-urgency}

Creating a sense of urgency is essential to successful change, and its importance is often underestimated by management. It should be fostered at the start of the change process (Kotter $\&$ Cohen, 2002). Interestingly, the graduate attribute mapping by Lawson et al. (2013) did not include urgency. We assume that, because graduate attribute mapping is a requirement of the government, a sense of urgency was already present.

In the Project we have divided urgency into intra-urgency (internal factors) and inter-urgency (external factors). Intra-urgency was created in the Project when we undertook two surveys, one of teaching staff and the other of first-year students regarding their preparedness for study. Results from both indicated that many students did not have the mathematics background assumed in first-year units. This was also consistent with a sense of inter-urgency, as this issue was not isolated to our regional university but was a sector-wide issue. The Australian Chief Scientist, at the National Forum on Assumed Knowledge in Maths held at the University of Sydney in February 2014, called for action by universities and staff to address the declining rates of students studying mathematics in Australian schools. This was reported in the national newspapers (McNeilage, 2014), thus increasing the momentum around this issue. Interurgency increased for staff when a respected expert spoke to university staff at the Call-toaction Seminar, reinforcing this as a national issue with 40 academic staff from four Schools attending (Table 1). This laid the foundations for the remainder of the project, with many staff expressing the wish to embrace change because they recognised that the problems extended beyond their regional university, and were sector wide.

\section{Outcome 2: Guiding team}

The authors have similar educational background, both holding a post-graduate qualification in higher education as well as science degrees, and are passionate about QS development. Independently we have been involved in the scholarship of teaching and learning (SoTL), and in research into the development of QS in particular. The formal roles as First-Year Coordinators enabled us to lead the Project.

\section{Outcome 3: Vision}

In order to foster a culture for change it is important to share the same vision (Yielder \& Codling, 2004). The authors initially developed a shared vision about the importance of developing QS, which was shared with our Deputy Head of School who is a leader in Agriculture Education. The authors refined this collective vision through discussion with staff attending the Initial Workshop (Table 1). 
Table 1. Alignment of the Project with the Merged Conceptual Framework (outcomes) from Figure 1. In bold are key words from the benchmarking framework for distributed leadership (Jones et al. 2014). Numbers in the first column represent the order activities were performed. Items in assess (7) and emergent (8) were not numbered as evidence was collected throughout Project.

\begin{tabular}{|c|c|}
\hline Sequential steps in the Project & Outcome no. \\
\hline $\begin{array}{l}\text { 1. Authors developed an online First-Year Experience Questionnaire about students' mathematical } \\
\text { preparedness for study for both students and staff at UNE. }\end{array}$ & 1 Intra-urgency \\
\hline $\begin{array}{l}\text { 2. Authors attended National First-Year Mathematics workshop, where the presentation by Australian } \\
\text { Chief Scientist increased urgency. }\end{array}$ & 1 Inter-urgency \\
\hline 3. Authors chose to collaborate on this Project in our roles as First-Year Science Coordinators. & 2 Guiding team \\
\hline 4. Authors formulated clear vision/goals of the Project based on our research. & 3 Vision \\
\hline $\begin{array}{l}\text { 5. The Project gained support from formal leaders/executives: senior management (Heads and Deputy } \\
\text { Heads of Schools), Pro Vice Chancellor Academic, external granting body. }\end{array}$ & 4 Engage \\
\hline $\begin{array}{l}\text { 6. With a context of trust, the authors built a culture of respect for each other, modelled that trust, and } \\
\text { then built trust across the two schools. }\end{array}$ & 5 Enable \\
\hline $\begin{array}{l}\text { 7. Requested support from formal leaders (Heads of Schools) to encourage staff participation; Deputy } \\
\text { Heads of Schools (including leader in agriculture education) attended workshops. }\end{array}$ & 4 Engage \\
\hline $\begin{array}{l}\text { 8. Initial Workshop } \\
\text { a. Established conversation with staff, thus building urgency regarding institutional issues. } \\
\text { b. Collectively developed a shared meaning of QS and refined vision for change. } \\
\text { c. Built trust and respect as } 35 \text { academics from } 15 \text { science disciplines collaborated (including } 8 \\
\text { agriculture staff). }\end{array}$ & $\begin{array}{l}1 \text { Intra-urgency } \\
3 \text { Vision } \\
4 \text { Engage } \\
5 \text { Enable }\end{array}$ \\
\hline $\begin{array}{l}\text { 9. Call-to-action Seminar by nationally recognised discipline expert built sense of urgency for change. } \\
\text { Engaged } 40 \text { academic staff from four schools, including } 8 \text { agriculture staff. }\end{array}$ & $\begin{array}{l}1 \text { Inter-urgency } \\
4 \text { Engage }\end{array}$ \\
\hline $\begin{array}{l}\text { 10. Teaching staff accepted the need for change willingly. Authors encouraged collaborative } \\
\text { relationships and facilitated collaborative decision-making in the Project. } \\
\text { Involved people: with support of senior management, authors convinced staff of the mapping process' } \\
\text { usefulness, effectiveness, benefits and potential for curriculum change. Authors identified Champions in } \\
\text { each discipline, to share practices and promote the benefits that come from engaging with the mapping of } \\
\text { QS. }\end{array}$ & 5 Enable \\
\hline $\begin{array}{l}\text { 11. Designed participative processes such as discipline-based Workshops, where relevant teaching staff } \\
\text { determined graduate-level QS for } 10 \text { courses, including three agriculture degrees. Levels of attainment } \\
\text { and QS list were refined using staff input and reflection on process by authors. }\end{array}$ & 6 Enact \\
\hline 12. Functional expert (professional staff member) coded the computerised mapping tool. & 4 Engage \\
\hline 13. Unit (subject) mapping tool developed, tested and evaluated. & 6 Enact \\
\hline $\begin{array}{l}\text { 14. Provided support through training in using mapping tool at Mapping Workshops. First-year unit } \\
\text { coordinators used the tool to map when each quantitative skill was taught, practiced and assessed. The } \\
\text { mapping process was sold to time-poor academics as a simple process that would yield a wealth of } \\
\text { information. The Project delivered this. }\end{array}$ & 6 Enact \\
\hline $\begin{array}{l}\text { 15. Systems were integrated and aligned to School policies and processes. For example, the mapping } \\
\text { fed into the review of the first-year mathematics curriculum. Furthermore, through the Action Workshop } \\
\text { for Agriculture, both degree and school-level curriculum changes, such as the timing of when QS were } \\
\text { taught, were made. In addition, staff developed a shared meaning of QS and, as a consequence of the } \\
\text { inclusive process, felt ownership of the process. }\end{array}$ & 6 Enact \\
\hline $\begin{array}{l}\text { Increased engagement throughout the Project was demonstrated through workshop attendance and } \\
\text { participation among Agriculture academics, as well as academics from cognate (service) disciplines. } \\
\text { Increased collaboration was evident: over half of academics in the two science schools participated in } \\
\text { the QS Project. Silos were broken down, and agriculture academic staff collaborated with service-teaching } \\
\text { academics. } \\
\text { Growth in leadership capacity occurred as the authors obtained formal leadership positions with the } \\
\text { Schools. They presented two conference presentations on their leadership roles. }\end{array}$ & 7 Assess \\
\hline $\begin{array}{l}\text { Reflective process was built into formal practice as the authors constantly adjusted the Project based on } \\
\text { formal and informal feedback from participants and observers to ensure all staff felt ownership of the } \\
\text { process, and the Project continuously improved. } \\
\text { Results from the Project were embedded into curriculum change. } \\
\text { Leadership development in QS occurred across the two schools, and leadership emerged beyond the } \\
\text { Project as the authors formalised leadership roles in School Teaching and Learning. } \\
\text { Passion for Scholarship of Teaching and Learning (SoTL) has been fostered and sustained in both schools } \\
\text { through additional grants and forums. The development of SoTL in the Sciences receives ongoing support } \\
\text { from the Heads of School. }\end{array}$ & 8 Emergent \\
\hline
\end{tabular}




\section{Outcome 4: Engage}

Academic staff are often sceptical of explicit organisational leadership by those in formal positions of authority (such as vice-chancellor, dean and head of department) and frequently look elsewhere for the leadership of academic work (Bolden, Jones, Davis, \& Gentle, 2015, p.6). However, some critics think that distributed leadership theory does not adequately deal with power and it may simply be a 'facade designed to win commitment to objectives determined elsewhere' (Corrigan, 2013, p.70). However, in the Project there was no facade. Although the authors initiated the Project, as junior academics, it was essential that we gained the support of senior management within the Schools and University because we needed to develop a shared vision and engage staff at all levels based on both the intra- and inter-urgency for change. The senior management (formal leaders) fully and openly supported the Project. Thirty-five academic staff (discipline experts) attended the Initial Workshop, which included seven agriculture staff. In addition, 40 academic staff from four schools attended the Call-toaction workshop, including eight agriculture staff. The authors also engaged with a discipline expert in computing to create the mapping software.

\section{Outcome 5: Enable}

To create a trusting environment the authors firstly built a culture of respect for each other, modelled that trust, and then built trust across the two schools. Clear rules regarding behaviour by the participants were outlined. At the start of the group discussions in the Initial Workshop each academic put on a black hat to expel any negative thoughts (de Bono, 1995). Participants completed this activity and then self-regulated to avoid black hat behaviour in other activities. Project observers noted many behaviours in the workshop conversations that indicated collaboration among academics took place in a trusting and respectful environment. These included joining in; encouraging others; taking turns; asking for help; asking questions; clarifying; negotiating; convincing others; listening; summarising; and criticising ideas not people. Through the culture of trust and respect, the authors facilitated collaborative relationships and encouraged collaborative decision-making, thus allowing staff to accept the need for change willingly. All first-year unit coordinators and course (degree) coordinators were active participants throughout the process.

\section{Outcome 6: Enact}

Distributed leadership is enacted through staff involvement and support, along with process design and implementation (Jones et al., 2014). At the Initial Workshop 35 academics, including eight from agriculture disciplines, were allocated to multidiscipline tables of six with one mathematician or statistician per table. This broke down the traditional discipline silos, allowed staff to realise the issues were across disciplines and schools, and built a sense of unity and increased intra-urgency. Academic A wrote in the Final Questionnaire "The collegiality and constructiveness of interdisciplinary discussions was largely due to the excellent organisation of this project."

The authors identified and worked closely with at least one Champion in each of the 13 disciplines to gain support for the overall Project. Staff were involved and supported at the Initial Workshop, Discipline-based workshops to determine graduate QS, Unit Mapping and Course Action Workshops. Following the Unit Mapping workshop Academic B wrote:

"The potentially onerous task of data submission in relation to the various disciplines and units was made very easy for staff who participated - no doubt because of the hard-work invested beforehand by the team in designing the online collection instruments. Their readiness to support staff while using the instruments was also outstanding." 
The Course Mapping Workshop for Agriculture degrees was designed and implemented to encourage the participation of experts in the agriculture disciplines with other first-year science disciplines. Discussion allowed the Agriculture academics to gain a clearer understanding of the mathematician's perspective, such as how abstract mathematical thinking allows students to apply QS in a variety of contexts. Similarly to Gupta and Adams (2016, p.9), the Agriculture academics spoke of the need for 'authentic, real world examples' in Agriculture to allow students to contextualise the QS.

Discussion occurred regarding the need for additional support for distance students and the sequencing of units for part-time enrolments. This was consistent with the findings of Gupta and Adams (2016), who identified the difficulties of distance Agriculture students studying mathematics, because it is 'highly abstract, fundamentally sequential and based on visualspatial symbolic notation' (p.5). Mathematics staff have since implemented Maplesoft ${ }^{\mathrm{TM}}$ Maple TA software, an online testing tool to support distance students with rapid tailored feedback. Through course mapping, it became evident that some QS that were assumed knowledge in chemistry were first taught in mathematics units, so the part-time course plans in Agriculture were updated requiring students to complete the mathematics unit before enrolling in chemistry.

\section{Outcome 7: Assess}

Various sources of evidence were used to assess the success of the distributed leadership approach of the Project for increased engagement (participation), collaboration and leadership capacity. The participation rate in the Project was substantial, with over half of the academics from both schools being involved, showing increased engagement (Table 1, outcome 7). For example, 28 first-year unit coordinators mapped their units using the online mapping tool, which allowed 10 courses, including three agriculture degrees to be mapped. In reporting the outcomes from the QS mapping process, Reid and Wilkes (2016) stated that the Project helped address issues that impact on the ability of students to apply mathematics in other areas of the curriculum by establishing and facilitating inter-disciplinary collaboration and developing a 'shared meaning' of QS among academics. This Project impacted on the Agriculture disciplines in several ways, resulting in changes in degree plans and the development of new mathematics units.

Nine academics responded to the Final Project Evaluation Questionnaire. All of them agreed or strongly agreed that "the project activities were useful in promoting interdisciplinary discussion about QS in science disciplines" and that "the organisation of the project activities facilitated constructive staff participation."

In summary, the high number of staff engaging with the process, the mapping of all first-year units, the resultant changes to the first-year curriculum, and the development of a holistic approach to curriculum mapping by academics are all evidence of the success of the Project.

\section{Outcome 8: Emergent}

To build sustainable leadership in higher education, 'a new, more participative and collaborative approach to leadership is needed' (Jones, Lefoe, Harvey, \& Ryland, 2012, p.68). Distributed leadership provides one such approach. The Project has shown emergent properties since its completion. Firstly, all academics who contributed to the Project and responded to the Final Project Evaluation Questionnaire stated that they had "engaged in further discussions that were not part of the project activities with colleagues within my discipline about students' QS development". Secondly, the mapping tool designed for the Project has been adapted so that it can be used for mapping any skill such as graduate attributes or learning outcomes. It is freely available (https://www.une.edu.au/about-une/faculty-of-science-agriculture-business- 
and-law/school-of-science-and-technology/qs-mapping) and is currently being used in two separate mapping projects at UNE. Finally, the Project has shown sustainability by the permanent appointment of a First-Year Coordinator in both science schools, who keep QS development and transition pedagogy on the agenda. Following the success of the Project, the authors and two additional staff members have begun working with staff to map the QS across all years of the undergraduate degrees in the two Schools.

\section{Non-linear process}

This paper has detailed the alignment of the Project with the Merged Conceptual Framework. However, it is important to note that the application of the Merged Conceptual Framework will not necessarily follow a linear path. By sequentially numbering the order in which tasks were completed in the Project (Table 1) and matching those steps with the outcomes, it is clear that we applied the Merged Framework in a non-linear manner. For example, although initially we sequentially achieved outcomes 1 through 5, we felt it important to return to outcomes 4 (engage), 1 (urgency), 3 (vision), then 4 (engage) and 5 (enable) (Figure 2), once we had gained support for the Project from formal leaders. This was to ensure continued academic buy-in and engagement, by seeking and acting on staff input. This reflective action, where the authors revisited outcomes, was built into the Project to ensure the ongoing ownership and buy-in by the academic staff.

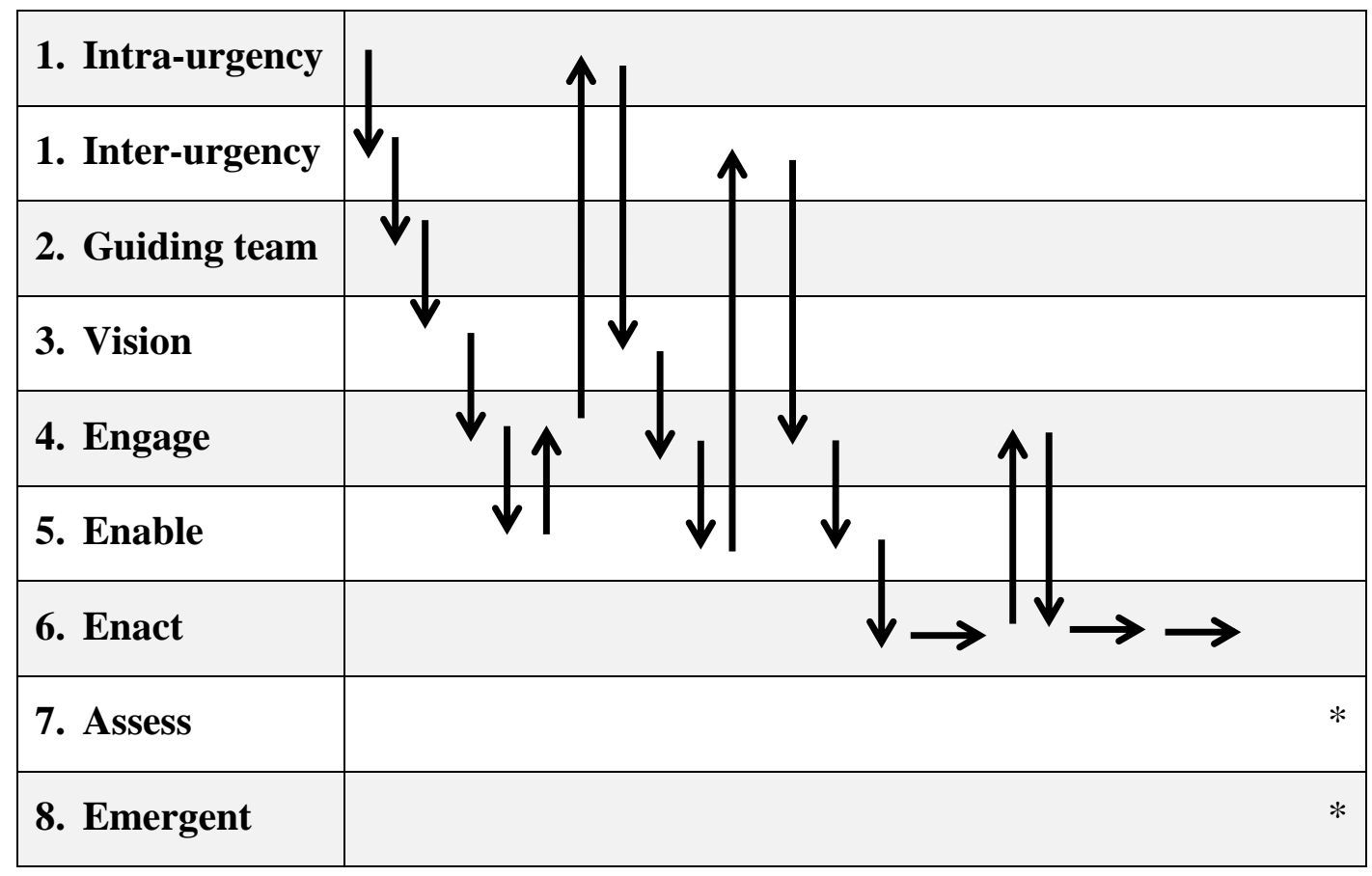

Figure 2. Diagram demonstrating the non-linear nature of the Project aligned to the Merged Conceptual Framework. * Evidence was collected throughout the Project for outcomes assess (7) and emergent (8).

\section{Conclusion}

This paper has demonstrated how the addition of change theory elements (increased urgency, constructing a guiding team, and having a clear vision) to the distributed leadership benchmarking framework proposed by Jones et al. (2014) was necessary for the development of a conceptual leadership framework that could be successfully applied to a curriculum 
mapping process. Measures of the success of this Project included the high level of engagement in the process by the majority of staff; the mapping of all first-year units and updating as required; and the holistic reflection on skill overlap and gaps by academics.

For the higher-education sector, we proposed dividing urgency into intra-urgency, which is generated from within the organisation, and inter-urgency, which is urgency from outside. Reflective action was built into the Project, and consequently the Merged Conceptual Framework was not followed in a sequential manner; some outcomes were revisited to ensure the academics had ownership of the process and continued to buy-in to the process. The benefits for Agriculture students were numerous, with the revision of degree plans, and the construction of more online resources to support the development of QS for both distance and on-campus students. Furthermore, the QS mapping informed the redevelopment of the firstyear mathematics curriculum. Staff have identified the graduate QS requirements for all agriculture degrees and gained a clearer shared understanding of the QS taught, practiced and assessed in first-year.

Although this paper reports on only one mapping project at a single regional university, the process can be easily adapted by other institutions for more comprehensive curriculum mappings beyond the first-year. For example, the Project has since been expanded to map QS across the curriculum for more than 150 core units in more than 40 science courses and majors at UNE. Future research will track the progression and development of QS in agriculture students throughout their course.

The Project would not have been as successful if all of the Merged Conceptual Framework outcomes had not been reached. In particular, gaining the support of senior management and the engagement and active participation of the academic staff, through the development of a sense of urgency and the creation of a shared vision, were crucial to its success.

\section{Acknowledgements}

Funding for this project has been provided by the Australian Government Office for Learning and Teaching (PP10-1640). The views expressed in this report do not necessarily reflect the views of the Australian Government Office for Learning and Teaching. The project had Human Ethics Approval (UNE HE:14-175). We gratefully acknowledge the input and support of our academic colleagues.

\section{References}

Advocacy Australian Mathematical Sciences Institute (2015). Dealing with Australia's Mathematical Deficit. The University of Melbourne: Melbourne. Retrieved from https://amsi.org.au/wpcontent/uploads/2014/07/policy-document-2014.pdf

Barrington, F. (2013). Year 12 mathematics student numbers 2003-2012. Australian Mathematical Sciences Institute: Melbourne. Retrieved from https://amsi.org.au/publications/participation-rates-in-year-12mathematics-2003-2012/

Bennett, N., Wise, C., Woods, P.A., \& Harvey, J.A. (2003). Distributed Leadership: a review of literature. National College for School Leadership, The Open University. http://oro.open.ac.uk/8534/1/bennettdistributed-leadership-full.pdf

Bolden, R. (2011). Distributed leadership in organizations: A review of theory and research. International Journal of Management Reviews, 13(3), 251-269. doi:10.1111/j.1468-2370.2011.00306.x

Bolden, R., Jones, S., Davis, H., \& Gentle, P. (2015). Developing and sustaining shared leadership in higher education. London, England: Leadership Foundation for Higher Education.

Botwright Acuña, T.L., Able, A. J., Kelder, J., Bobbi, P., Guisard, Y., Bellotti, W., McDonald, G., Doyle, R., Wormell, P., \& Meinke, H. (2014). Learning and Teaching Academic Standards Statement for Agriculture. Sydney, Australia: Office for Learning and Teaching. 
Botwright Acuña, T., McDonald, G., Kelder, J., \& Able, A. (2016). Implementing the threshold learning outcomes for Agriculture at two Australian universities. Journal of Teaching and Learning for Graduate Employability, 7(1), 2-21. doi:10.21153/jtlge2016vol7no1 art585

Boud, D., Brew, A., Dowling, R., Kiley, M., McKenzie, J., Malfroy, J., Ryland, K., \& Solomon, N. (2014). The coordination role in research education: emerging understandings and dilemmas for leadership. Journal of Higher Education Policy and Management, 36(4), 440-454. doi:10.1080/1360080X.2014.916466

Brown, G. (2009). Review of education in mathematics, data science and quantitative disciplines. Report to the Group of Eight Universities. O'Connor, Australia: Group of Eight (Australia). Retrieved from http://www.go8.edu.au/_documents/go8-policy-analysis/2010/go8mathsreview.pdf

Clay, B. (2017). John Kotter: A pragmatic observer of managers' life worlds. In The Palgrave handbook of organizational change thinkers (pp. 1-14). Cham: Palgrave Macmillan.

Corrigan, J. (2013). Distributed leadership: Rhetoric or reality? Journal of Higher Education Policy and Management, 35(1), 66-71. doi:10.1080/1360080X.2013.748479

de Bono, E.(1995). Serious creativity. The Journal for Quality and Participation, 18(5), 12-18.

Fallows, S., \& Steven, C. (2000). Embedding a skills programme for all students. In S. Fallows \& C. Steven (Eds.), Integrating key skills in higher education: employability, transferable skills and learning for life (pp. 17-32). London: Kogan Page.

Gosling, J., R. Bolden, \& G. Petrov. 2009. Distributed leadership in higher education: What does it accomplish? Leadership, 5(3), 299-310. doi:10.1177/1742715009337762

Gronn, P. (2002). Distributed leadership. Second International Handbook of Educational Leadership and Administration. London, England: Kluwer Academic Publishers.

Gupta, M., \& Adams, P. (2016). Enhancing engagement of agricultural students in learning mathematics. Sydney, Australia: Office for Learning and Teaching.

Jaafar, R., Toce, A., \& Polnariev, B. A. (2016). A multidimensional approach to overcoming challenges in leading community college math tutoring success. Community College Journal of Research and Practice, 40(6), 534-549. doi:10.1080/10668926.2015.1021406

Jones, S., Hadgraft, R., Harvey, M., Lefoe, G., \& Ryland, K. (2014). Evidence-based benchmarking framework for a distributed leadership approach to capacity building in learning and teaching. Sydney, Australia: Australian Government Office for Learning and Teaching.

Jones, S., Lefoe, G., Harvey, M., \& Ryland, K. (2012). Distributed leadership: A collaborative framework for academics, executives and professionals in higher education. Journal of Higher Education Policy and Management, 34(1), 67-78. doi:10.1080/1360080X.2012.642334

Kift, S., Nelson, K., \& Clarke, J. (2010). Transition pedagogy: A third generation approach to FYE- A case study of policy and practice for the higher education sector. The International Journal of First Year in Higher Education, 1(1), 1-20. doi:10.5204/intjfyhe.v1i1.13

King, D., \& Cattlin, J. (2014) National forum on assumed knowledge in mathematics report. Melbourne, Australia: FYiMaths Project.

Knight, P.T., \& Trowler, P.R. (2001). Departmental leadership in higher education. Buckingham, England: SRHE and Open University Press.

Kotter, J. P. (2014). Accelerate: Building strategic agility for a faster-moving world. Boston: Harvard Business Review Press.

Kotter, J.P., \& Cohen, D.S. (2002). The heart of change: Real life stories of how people change organisations. Boston: Harvard Business School Press.

Lawson, R., Taylor, T., Fallshaw, E., French, E., Hall, C., Kinash, S., \& Summers, J. (2013). Hunters \& gatherers: Strategies for curriculum mapping and data collection for assurance of learning. Sydney: Australian Government, Office for Learning and Teaching.

Leitch, R., \& Day, C. (2000). Action research and reflective practice: Towards a holistic view. Educational Action Research, 8(1), 179-93. doi:10.1080/09650790000200108

Matthews, K. E., Belward, S., Coady, C., Rylands, L. \& Simbag, V. (2012). The state of QS in undergraduate science education: findings from an Australian study. Sydney: Australian Government, Office for Learning and Teaching.

McNeilage, A. (2014, February 14). Dwindling maths standards concern of national importance. The Sydney Morning Herald. Retrieved from https://www.smh.com.au

Nicholls, A., \& Nicholls, H. (1981). Developing a curriculum: A practical approach. London: George Allen \& Unwin Ltd.

Ramsden, P. (1988). Learning to lead in higher education. London: Routledge.

Reid, J., \& Wilkes, J. (2016). Developing and applying QS maps for STEM curricula, with a focus on different modes of learning. International Journal of Mathematical Education in Science and Technology, 47(6), 837852. doi:10.1080/0020739X.2016.1144814 
International Journal of Innovation in Science and Mathematics Education, 27(4), 14-26, 2019

Yielder, J., \& Codling, A. (2004). Management and leadership in the contemporary university. Journal of Higher Education Policy and Management, 26(3), 315-328. doi:10.1080/1360080042000290177 